\title{
Soft Drink, Software and Softening of Teeth - a Case Report of Tooth Wear in the Mixed Dentition Due to a Combination of Dental Erosion and Attrition
}

\author{
D. L. Gambon ${ }^{1, *}$, H. S. Brand ${ }^{2}$ and A.V. Nieuw Amerongen ${ }^{2}$ \\ ${ }^{I}$ Bambodino Paediatric Dental Clinic, Rotterdam, the Netherlands. ${ }^{2}$ Department of Oral Biochemistry. Academic Centre \\ for Dentistry (ACTA), Amsterdam, The Netherlands
}

\begin{abstract}
This case report describes a 9-year-old boy with severe tooth wear as a result of drinking a single glass of soft drink per day. This soft drink was consumed over a period of one to two hours, while he was gaming intensively on his computer. As a result, a deep bite, enamel cupping, sensitivity of primary teeth and loss of fillings occurred. Therefore, dentists should be aware that in patients who are gaming intensively, the erosive potential of soft drinks can be potentiated by mechanical forces leading to excessive tooth wear.
\end{abstract}

Keywords: Erosion, soft drink, tooth wear, attrition.

\section{INTRODUCTION}

Tooth wear can be induced by erosion (chemical loss of dental hard tissue by an acid without bacterial involvement), attrition (physical wear through tooth-tooth contact) and abrasion (physical wear produced by interaction between teeth and another material) $[1,2]$. Clinically it can be difficult for dentists to determine the major cause of tooth wear, although the appearance and the location of tooth wear may be helpful [3]. Interaction between erosive and mechanical wear is considered to be important [2].

There is increasing concern over the high prevalence of dental erosion in children, and the prevalence seems to be increasing [4-7]. In Australia, the prevalence of erosion in the deciduous dentition was recently found to be as high as $68 \%$ [8].

Several studies indicate a relation between dental erosion and a high consumption of cola-type and other acid containing soft drinks $[9,10]$. In vitro, exposure of human enamel to citric acid solutions results in a considerable reduction in enamel hardness [11].

This case report presents a child, whose behaviour potentiated the erosive potential of soft drink consumption.

\section{CASE REPORT}

A 9-year-old boy having caries was referred to a paediatric dental clinic after two previous extractions in a general practice. He was a healthy child without any medication, functioning psychologically and emotionally well. He liked to play soccer and was fond of playing computer games.

Intra-oral examination revealed a mixed dentition with severe tooth wear and caries in the primary molars. A deep bite, enamel cupping and attrition signs and a flattened sur-

\footnotetext{
*Address correspondence to this author at the Bambodino Paediatric Dental Clinic, Meerum Terwogtlaan 133, 3056 PP Rotterdam, The Netherlands; Tel: +31 10 4334243; Fax: +31 104113957 ;

E-mail: dien.gambon@kpnmail.nl
}

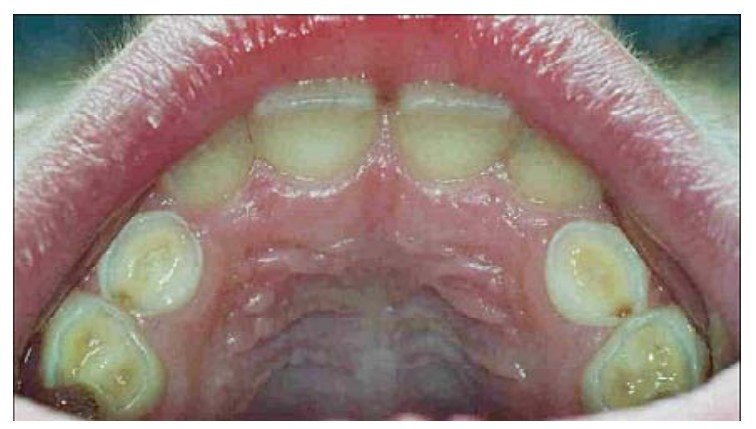

A

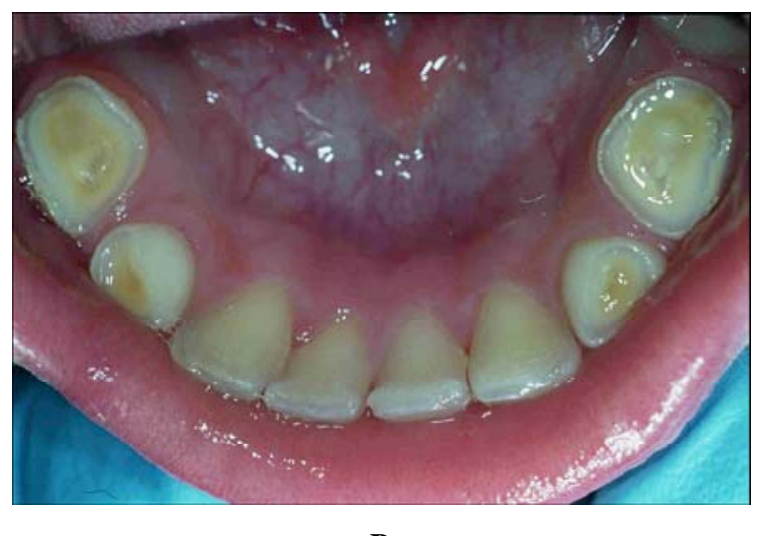

Fig. (1). Dental cupping and caries in the upper (A) and lower jaw (B).

face were observed (Figs. 1 and 2). The 84 showed an occlusal surface with a thin, sharp edge of enamel (Fig. 3A). The radiographs did not show pulp exposure.

Only one week later, the surface of the 84 was already flatter (Fig. 3B). During this dental session, the molars were restored with a resin-based material $\left(\right.$ Dyract $^{\circledR}$ compomer, De Trey, Konstanz, Germany) [7]. At the same time, the boy and his mother were asked to record his consumption pattern 


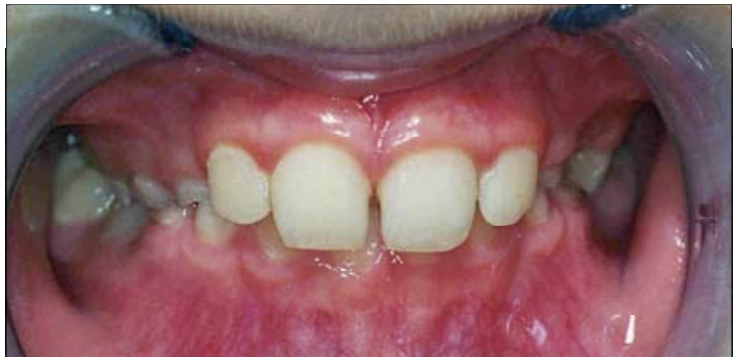

$\mathbf{A}$

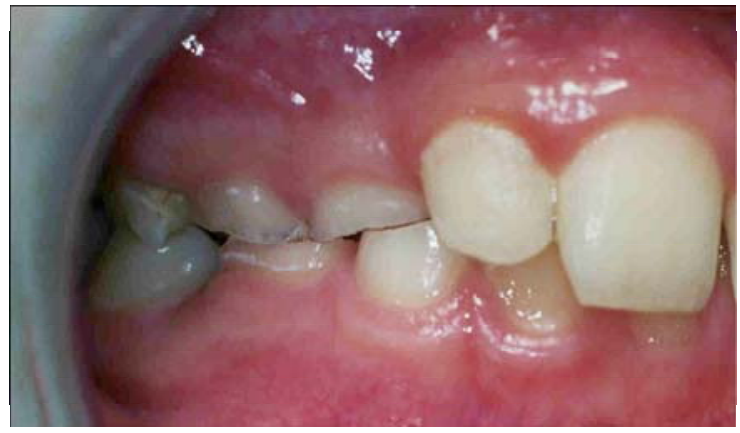

B

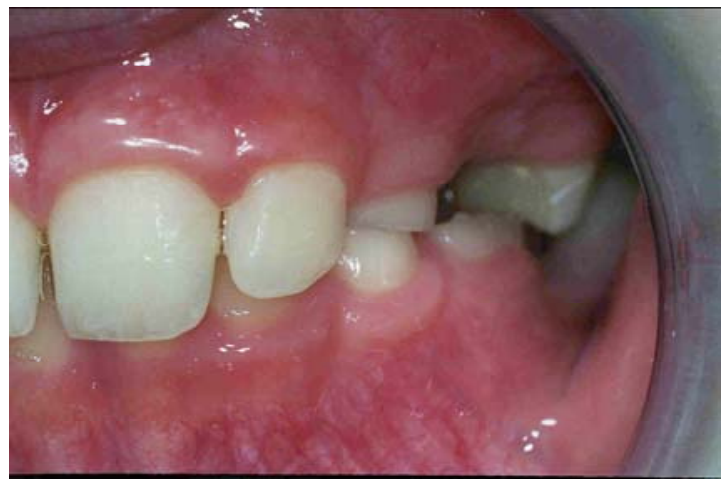

C

Fig. (2). Deep bite front (A), right (B) and left (C).

in a 6-day food diary. Although analysis of his diet didn't explain the clinical observations, the newly placed fillings came loose within several weeks, and the tooth wear continued.

When questioned in detail, the boy told that he consumed only one glass of soft drink per day over a period of one to two hours while he was gaming on his computer intensively. Incidentally, he was holding the soft drink over his teeth for a moment.

After personal advice, the boy changed his consumption pattern. This stopped the progression of caries. However, two years later, the tooth wear of the deciduous dentition had progressed (Fig. 4).

\section{DISCUSSION}

This case report describes a young boy with caries and tooth wear of unknown aetiology. The 6-day food diary revealed approximately nine eating and drinking moments per day, with $60 \%$ sugar containing food. This frequent and

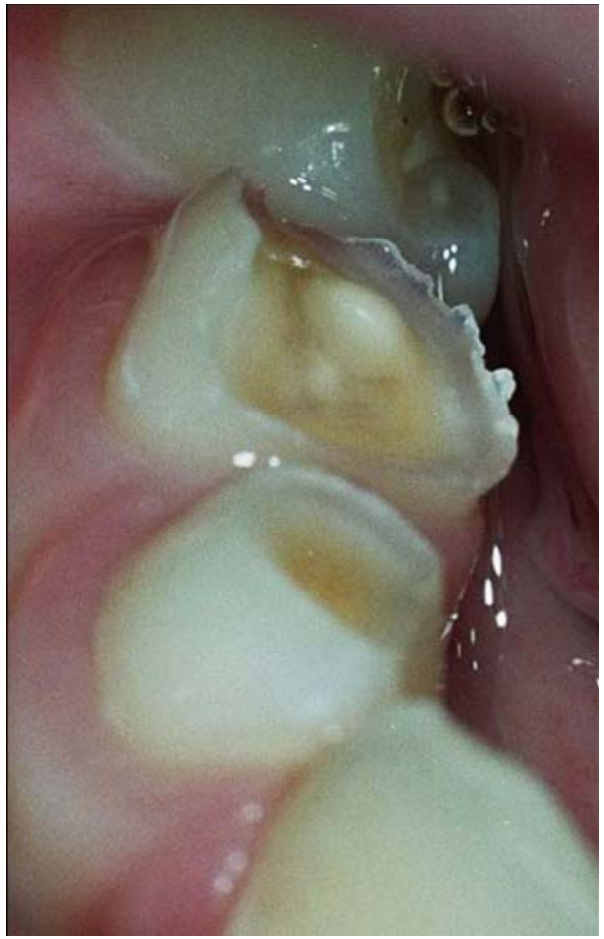

A

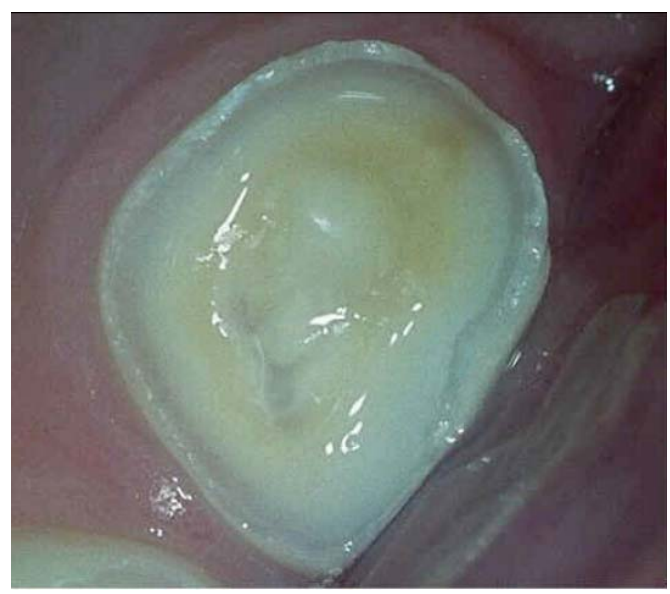

B

Fig. (3). Occlusal wear of the 84 during the initial presentation (A) and during the subsequent visit one week later $(\mathbf{B})$.

large amount of sugar-intake could explain the observed progression of dental caries. The food diary provided evidence for a relatively modest consumption of soft drinks. However, observation of cupped lesions in young people indicates active dental erosion [12,13]. The tooth wear of the first primary mandibular molars showed a pattern, different from dental cupping. The occlusal surface of the 84 , with a sharp edge of enamel became flat within one week. This suggests that both demineralization and mechanical wear were involved in the loss of enamel $[14,15]$. It is wellrecognised that interactions between erosion and attrition can contribute strongly to clinically-observed patterns of tooth wear [2]. In vitro, eroded human enamel is more sensitive to the mechanical stress [16]. 


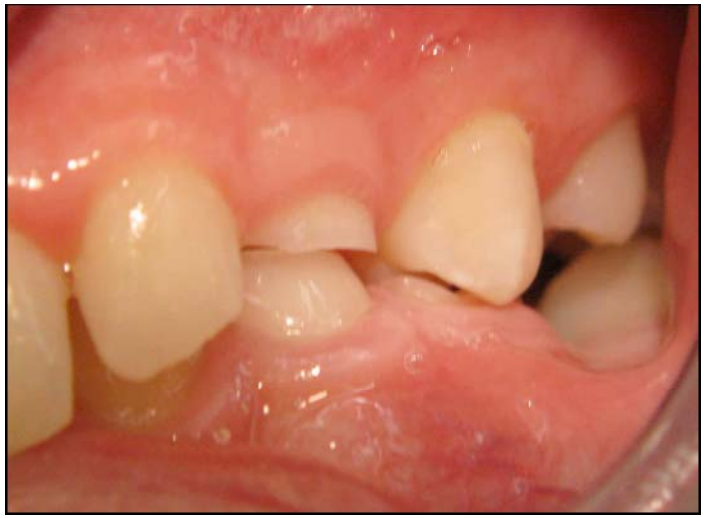

Fig. (4). Primary molars 64, 75 and premolars 25, 34 (two years after initial presentation).

In our case, the stress of computer gaming may have reduced the salivary flow rate [17]. Saliva plays a major protective role against tooth wear. It functions as a lubricant and is able to dilute and to buffer acidic drinks. Salivary proteins are also involved in building a protective pellicle layer on the enamel surface [18]. Therefore, a reduction in salivary flow rate may potentiate tooth wear by erosion and attrition [19].

Deciduous tooth enamel is softer than permanent enamel [20], and a higher susceptibility of deciduous enamel to citric acid has been reported [21]. In addition, the salivary calcium concentration is lower in children than adults, which means that children have a higher risk of demineralization [22].

When the boy changed his consumption pattern after dietary advice, the progression of caries stopped but the tooth wear progressed over the next two years. This suggests that dental attrition was not stopped by dietary counselling, emphasizing that factor(s) other than diet might have contributed to the problem, like habits or reduced salivary flow rate. A systemic disease, or its medical treatment, can probably be excluded as cause of the progression in tooth wear, because the boy appeared healthy and didn't use any kind of medication.

This case report illustrates that behaviour can potentiate the clinical tooth wear of consuming a relatively small volume of soft drinks. This information is of use for dentists counselling juvenile patients with dental erosion.

\section{REFERENCES}

[1] Ten Cate JM, Imfeld T. Dental erosion, summary. Eur J Oral Sci 1996; 104: 241-4.
[2] Addy M, Shellis RP. Interaction between attrition, abrasion and erosion in tooth wear. Monogr Oral Sci 2006; 20: 17-31.

[3] O'Sullivan E, Milosevic A. UK national clinical guidelines in paediatric dentistry: diagnosis, prevention and management of dental erosion. Int J Paediatr Dent 2008; 18 (suppl 1): 29-38.

[4] Deery C, Wagner ML, Longbottom C, Simon R, Nugent ZJ. The prevalence of dental erosion in a United Sates and a United Kingdom sample of adolescents. Pediatr Dent 2000; 22: 505-10.

[5] Nunn JH, Gordon PH, Morris AJ, Pine CM, Walker A. Dental erosion: changing prevalence? a review of British national childrens' surveys. Int J Paediatr Dent 2003; 13: 98-105.

[6] Jaeggi T, Lussi A. Prevalence, incidence and distribution of erosion. Monogr Oral Sci 2006; 20: 44-65.

[7] Johansson A, Johansson AK, Omar R, Carlsson GE. Rehabilitation of the worn dentition. J Oral Rehabil 2008; 335: 548-66.

[8] Kazoullis S, Seow WK, Holcombe T, Newman B, Ford D. Common dental conditions associated with dental erosion in schoolchildren in Australia. Pediatr Dent 2007; 29: 33-9.

[9] Dugmore CR, Rock WP. A multifactorial analysis of factors associated with dental erosion. Br Dent J 2004; 196: 283-6.

[10] Jensdottir T, Arnadottir IB, Thorsdottir I, et al. Relationship between dental erosion, soft drink consumption, and gastroesophageal reflux among Icelanders. Clin Oral Investig 2004; 8: 91-6.

[11] Barbour ME, Parker DM, Allen GC, Jandt KD. Human enamel dissolution in citric acid as a function of $\mathrm{pH}$ in the range $2.30 \leq \mathrm{pH}$ $\leq 6.30$ - a nanoindentation study. Eur J Oral Sci 2003; 111: 258-62.

[12] Khan F, Young WG, Law V, Priest J, Daley TJ. Cupped lesions of early onset dental erosion in young southeast Queensland adults. Aust Dent J 2001; 46: 100-7.

[13] Yip HK, Smales RJ, Kaidnos JA. Management of tooth tissue loss from erosion. Quintessence Int 2002; 33: 516-20.

[14] Amaechi BT, Higham SM, Edgar WM. Influence of abrasion in clinical manifestation of human dental erosion. J Oral Rehabil 2003; 30: 407-13.

[15] Litonjua LA, Andreana S, Bush PJ, Cohen RE. Tooth wear: attrition, erosion and abrasion. Quintessence Int 2003; 34: 435-46.

[16] Heurich E, Beyer M, Jandt KD, et al. Quantification of dental erosion: a comparison of stylus profilometry and confocal laser scanning microscopy (CLSM). Dent Mater 2010; 26: 326-36.

[17] Bosch JA, de Geus EJC, Veerman ECI, Hoogstraten J, Nieuw Amerongen AV. Innate secretory immunity in response to laboratory stressors that evoke distinct patterns of cardiac autonomic activity. Psychosom Med 2003; 65: 245-58.

[18] Finke M, Parker DM, Jandt KD. Influence of soft drinks on the thickness and morphology of in situ acquired pellicle layer on enamel. J Colloid Interface Sci 2002; 251: 263-70.

[19] O'Sullivan EA, Curzon MEJ. Salivary factors affecting dental erosion in children. Caries Res 2000; 34: 82-7.

[20] Lippert F, Parker DM, jandt KD. Susceptibility of deciduous and permanent enamel to dietary acid-induced erosion studied with atomic force microscopy nanoindentation. Eur J Oral Sci 2004; 112: 61-6.

[21] Johansson AK, Sorvari R, Birkhed D, Meurman JH. Dental erosion in deciduous teeth - an in vivo and in vitro study. J Dent 2001; 29: $333-40$.

[22] Anderson P, Hector MP, Rampersad MA. Critical pH in resting and stimulated whole saliva in groups of children and adults. Int $\mathrm{J}$ Paediatr Dent 2001; 11: 266-73 